\title{
A política de alfabetização bilíngue: histórico, ações para a formação de professores indígenas e a produção didática
}

\author{
The bilingual literacy policy: history, initiatives for the \\ training of indigenous teachers and the pedagogical \\ production
}

\author{
Rosangela Célia Faustino ${ }^{1}$ \\ Marcos Gehrke ${ }^{2}$ \\ Maria Simone Jacomini Novak ${ }^{3}$
}

DOI: http://dx.doi.org/10.20435/tellus.vi43.735

Resumo: Seguindo estratégias internacionais desenhadas desde o início do século XX, há no Brasil uma política de Educação Escolar Indígena, fundamentada na interculturalidade, com foco na alfabetização bilíngue. Porém, considerando a diversidade sociolinguística do país, a histórica política de integração e, mais recentemente, o reconhecimento aos processos próprios de aprendizagem, os programas de alfabetização bilíngue requerem iniciativas locais, articuladas com a formação de professores que resulta em produção de recursos pedagógicos diferenciados. Neste texto, apresentamos um histórico da política de alfabetização bilíngue discutindo documentos e encaminhamentos que culminaram na criação da ação Saberes Indígenas na Escola, inaugurando uma produção didática elaborada pelos professores. Os resultados mostram que a produção de materiais nas próprias comunidades, além de considerar as variações dialetais, oportuniza a criação de fecundos espaços de diálogos e pesquisas dos professores indígenas entre si, com sábios mais velhos, envolvendo jovens e crianças sobre questões culturais e ensejando, ainda, diálogos sobre ensino e aprendizagem escolar na comunidade.

Palavras-chave: bilinguismo; alfabetização; indígenas Kaingang; recursos pedagógicos.

Abstract: Following international strategies designed since the beginning of

1 Universidade Estadual de Maringá (UEM), Maringá, Paraná, Brasil.

2 Universidade Estadual do Centro Oeste (UNICENTRO), Guarapuava, Paraná, Brasil.

3 Universidade do Paraná (UNESPAR), Paranavaí, Paraná, Brasil. 
the 20th century, there is an Indigenous School Education policy in Brazil based on interculturality with a focus on bilingual literacy. However, considering the country's socio-linguistic diversity, historical integration policy, and, more recently, recognition of the own learning processes, bilingual literacy programs require local initiatives, linked to the training of teachers that result in the production of special pedagogical resources. In this text, we present the history of the bilingual literacy policy by discussing documents and guidelines that culminated in the creation of the Indigenous Knowledge at School initiative that started a pedagogical production prepared by the teachers. The results show that the production of materials in the communities themselves, in addition to taking into account the dialectal variations, makes it possible to create fertile spaces for dialogues and research among indigenous teachers with wise elders, involving young people and children on cultural issues, motivating also dialogues about school teaching and learning in the community.

Keywords: bilingualism; literacy; Kaingang indigenous; pedagogical resources.

\section{INTRODUÇÃO}

A abordagem sobre o bilinguismo e a alfabetização bilíngue entre grupos minoritários tem uma longa história. No Brasil, os jesuítas tiveram a preocupação de registrar elementos das línguas indígenas com as quais tiveram contato e, em alguns casos, produziram extensos vocabulários, como o de Antonio Ruiz de Montoya, no século XVII; porém, programas de alfabetização bilíngue com a participação dos professores indígenas no planejamento e na produção de materiais didáticos só foram desenhados séculos depois, em decorrência de movimentos de resistência, em que os povos lutaram para ter seus saberes e línguas reconhecidos, respeitados e presentes em sua educação escolar intercultural.

Historicamente, no Brasil, desde a ocupação dos territórios e os projetos mercantilistas de exploração e dominação, predomina a imposição das línguas, consideradas de prestígio (LISBÔA, 2017), sobre as línguas e culturas indígenas. A partir do final do século XX, algumas mudanças ocorreram na política educacional destinada aos povos indígenas e, neste sentido, é necessário compreendermos os movimentos sociais e as lutas indígenas que possibilitaram, nas últimas décadas do século XX, o reconhecimento das línguas indígenas e seus usos em processos de alfabetização.

Um importante acontecimento internacional que levou à discussão sobre a alfabetização bilíngue foi a Revolução Russa, no início do século XX. Considerando o analfabetismo naquele país, que abarcava cerca de $70 \%$ da 
A política de alfabetização bilíngue: histórico, ações para a formação de professores indígenas e a produção didática

população (BITTAR; FERREIRA JUNIOR, 2015), sendo maior este índice entre as mulheres, observou-se, a partir da revolução socialista de 1917, um movimento de valorização da instrução, com a defesa de que todos pudessem ter a oportunidade de aprender a ler e escrever e ter acesso a livros. No contexto revolucionário, houve a preocupação com a questão das diferentes línguas que passaram a compor a União das Repúblicas Socialistas Soviéticas (URSS), ensejando uma renovação linguística com a criação ou o fortalecimento de sistemas de escrita, produção de gramáticas e outros materiais didáticos bilíngues, destinados ao registro, alfabetização e valorização das línguas nas repúblicas que falavam diferentes idiomas (DESHERIEV, 1984).

Com esta iniciativa, mesmo em meio ao período das grandes guerras mundiais, os países capitalistas ocidentais se preocuparam com a mudança radical de perspectiva ocorrida em relação aos direitos sociais e linguísticos dos diferentes povos. Em 1919, criaram a Organização Internacional do Trabalho (OIT), com o objetivo de promover justiça social. Os Estados Unidos nomearam uma equipe interdisciplinar de pesquisadores para realizar um diagnóstico envolvendo questões sobre o uso das línguas indígenas nas escolas (MERIAN, 1928). A Europa iniciou uma nova discussão sobre como conduzir a questão das línguas minoritárias, visando traçar um programa de estudos, sugerir novas metodologias e estimular um trabalho positivo sobre o bilinguismo (RIES; HUGUES; SAER, 1932).

Findada a Segunda Grande Guerra Mundial, foi criada, em 1945, a Organização das Nações Unidas para a Educação, a Ciência e a Cultura (UNESCO), com o objetivo de fortalecer/disseminar ideais liberais e agregar direitos aos povos e culturas do mundo. Iniciou-se o patrocínio de estudos e pesquisas sobre culturas e línguas, bem como o financiamento de programas de alfabetização bilíngue (UNESCO, 1950; 1954).

Com a força destas organizações, os países-membros passaram a desenvolver pesquisas e algum tipo de programa de alfabetização bilíngue. No Brasil, em 1956 (BARROS, 1993), foi autorizada a entrada da missão evangélica Summer Institute of Linguistics (SIL), que já atuava no México com as populações indígenas, desde 1930, produzindo vocabulários e materiais de alfabetização em línguas indígenas.

Tanto a UNESCO como as demais organizações internacionais encarregadas de disseminar os ideais ocidentais de desenvolvimento no pós-guerra atuaram 
no sentido de construir uma política de alfabetização bilíngue. A Convenção 107, de 1957, da OIT, determinou, em seu Artigo 23, que deveria ser "[...] ministrado às crianças pertencentes às populações interessadas, ensino para capacitá-las a ler e escrever em sua língua materna" e, no Artigo 26, que "[...] serão utilizadas para esse fim traduções escritas e informações largamente difundidas nas línguas dessas populações" (OIT, 1957).

Neste contexto, o SIL se instalou entre os povos indígenas na América Latina. Na região sul do Brasil, houve a formação de monitores indígenas em missões ou por meio da Escola Normal Bilíngue Clara Camarão. Desde 1958, começou uma produção, pelos missionários, de materiais de alfabetização bilíngue: cartilhas, textos bíblicos, vocabulários e outros (FAUSTINO, 2006).

Neste texto, com pesquisa documental e bibliográfica, abordamos aspectos históricos das lutas sociais que levaram à aprovação de uma política de alfabetização bilíngue entre os povos indígenas e as mudanças ocorridas a partir dos anos de 1980/1990, com o reconhecimento, o respeito e a valorização da diversidade cultural e linguística dos povos indígenas ensejando a criação de Referenciais, Parâmetros e Diretrizes de formação de professores e produção de materiais bilíngues para a alfabetização nas línguas indígenas, fundamentados na interculturalidade.

\section{A POLÍTICA INTERNACIONAL DA ALFABETIZAÇÃO BILÍNGUE PARA POPULAÇÕES INDÍGENAS}

Nas primeiras décadas do século XX, após a União das Repúblicas Socialistas Soviéticas (URSS) ter, por meio de seus linguistas e pedagogos, investido em estudos e implantado programas de alfabetização bilíngue para falantes das línguas minoritárias (DESHERIEV, 1984), instituições internacionais ocidentais europeias iniciaram uma discussão sobre bilinguismo e sua importância na educação escolar. Uma Assembleia geral ocorrida em Genebra, em 1927 (RIES; HUGUES; SAER, 1932), pretendeu reposicionar as políticas linguísticas envolvendo as línguas minoritárias.

No mesmo período, nos Estados Unidos foi organizado um grupo de trabalho composto por especialistas de diferentes áreas do conhecimento, encarregados de realizar um levantamento das condições econômicas e sociais dos povos nativos, destacando-se questões sobre saúde, educação, situação das mulheres e outros. O resultado da ação foi publicado em um documento intitulado Merian Repport, 
A política de alfabetização bilíngue: histórico, ações para a formação de professores indígenas e a produção didática

em 1928 (COLLET, 2006). Na área da educação foram propostas inovações para a construção de projetos educacionais culturalmente adequados. Germinava ai, os fundamentos da interculturalidade e do bilinguismo na Educação Escolar Indígena.

Nas décadas seguintes, até meados dos anos de 1940, as economias centrais estiveram envolvidas com os conflitos oriundos da II Grande Guerra Mundial e seus desdobramentos. Findada a Guerra, em 1945, estas economias buscam o fortalecimento e a expansão do capitalismo pelo mundo. Para tanto, criaram a Organização das Nações Unidas (ONU), e outros organismos internacionais como a Organização das Nações Unidas para a Educação, a Ciência e a Cultura (UNESCO), que passou a produzir e divulgar documentos e tratados como a Declaração Universal dos Direitos Humanos.

Visando à valorização da diversidade cultural, foi lançado o documento The Race Question (UNESCO, 1950) como resultado dos trabalhos de um comitê de especialistas, oriundos de diferentes países, convidados por esta organização para realizarem estudos sobre diversidade cultural e um conjunto de proposições, fundamentadas cientificamente, que colocariam em debate o preconceito e promoveria os diferentes grupos humanos, com o objetivo de construir a "paz social" para o avanço da sociedade.

Em relação às minorias étnicas, as ações dos organismos destacaram a importância da preservação das línguas, lançando o documento intitulado Empleo de las Lenguas Vernáculas en la Enseñanza (UNESCO, 1954). Um importante teórico bielo-russo, Vigotski (2009), vinha, desde 1920, desenvolvendo estudos sobre as funções da linguagem e o bilinguismo, tendo afirmado que este potencializa a aprendizagem e o desenvolvimento da criança.

Na América Latina, experiências-piloto, com o uso das línguas indígenas na alfabetização e produção de cartilhas e outros materiais didáticos, baseados nas orientações de estudos científicos sobre bilinguismo, começaram a ser desenvolvidas (BARROS, 1993) por linguistas da agência missionária Summer Institute of Linguistics (SIL), financiados por empresários norte-americanos. Em 1956², o

\footnotetext{
4 A entrada do SIL no Brasil ocorreu na década de 1950, no período de transição do indigenismo de base positivista para o indigenismo com base no culturalismo norte-americano. "Darcy Ribeiro foi o principal representante do indigenismo de base antropológica no SPI e um dos principais aliados da missão" (BARROS, 2004, p. 26).
} 
SIL conseguiu fixar-se no Brasil e iniciar o trabalho de conversão dos índios aos protestantismo, concomitante à alfabetização bilíngue para e leitura da Bíblia em suas próprias línguas.

Em 1960, a Organização das Nações Unidas para a Educação, a Ciência e a Cultura aprovou a Convenção relativa à luta contra a discriminação no campo do ensino, e seu artigo $V$ estabeleceu que "deve ser reconhecido aos membros das minorias nacionais o direito de exercer atividades educativas que Ihes sejam próprias, inclusive a direção das escolas e, seguindo a política de cada Estado em matéria de educação, o uso ou o ensino de sua própria língua" (UNESCO, 1960).

Na sequência, foi aprovada a Convenção Internacional sobre a eliminação de todas as formas de discriminação racial e, com o Pacto Internacional dos Direitos Civis e Políticos da ONU (1966), foram consagradas normas de proteção aos direitos culturais, religiosos e linguísticos das minorias.

Em relação à política de codificação de línguas indígenas na América Latina e ao uso destas na alfabetização, a missão evangélica Summer Institute of Linguistics (SIL) atuava buscando acordos políticos para entrar nos países, ter acesso privilegiado às comunidades e realizar um trabalho de conversão dos indígenas, compelindo-os a abandonar suas crenças (religiões ancestrais), ler a Bíblia e ingressar no sistema de mercado.

Uma vez que pode ler e escrever, ainda que a princípio seja somente em sua própria língua, acaba o complexo de inferioridade [do índio]. Começa a se interessar em coisas novas. Se interessa em comprar artigos manufaturados - implementos, moinhos, roupas etc. Para fazer tais compras necessita trabalhar mais. A produção aumenta e logo o consumo também. A sociedade inteira, menos o cantineiro e o bruxo, tiram proveito. Descobre-se que o índio vale mais como homem culto do que como força bruta sumida na ignorância. (TOWNSEND, 1949, p. 43).

Em 1958, a missionária Ursula Wiesemann, do SIL, inicia estudos sobre a Língua Kaingang na Terra Indígena Rio das Cobras, Paraná - a maior do estado. O processo se dá com a instalação de uma "missão" em área próxima, para atração de algumas famílias com a oferta de moradias, área de lazer, instalação de escola, alimentos, roupas, serviços de saúde e igreja equipada. Em troca, essas famílias permitem que os missionários aprendam sua língua e ensinem suas crianças e jovens a ler e escrever. 
A política de alfabetização bilíngue: histórico, ações para a formação de professores indígenas e a produção didática

Tendo se apropriado da língua e elementos da cultura kaingang (WIESEMANN, 1959; 1960; 1964), e, inclusive, conseguido um nome próprio kaingang que, simbolicamente, ajuda a legitimar o missionário entre os indígenas; são produzidas cartilhas para ensino da leitura e escrita, como a intitulada To ke jé - Cartilha Kaingang, publicada em Língua Kaingang, sob o patrocínio do Serviço de Proteção ao Índio (SPI) no início dos anos de 1960. A estes materiais foram sendo agregados hinos e evangelhos publicados em línguas indígenas.

Em 1972, o SIL conseguiu concluir sua negociação com o governo militar e firmou convênio com a Fundação Nacional do Índio (FUNAI), contando já com mais de uma década de trabalho missionário entre indígenas. No tocante à educação, com base nas orientações das organizações internacionais, o Estatuto do Índio, publicado em 1973, definiu que:

Art. 49. A alfabetização dos índios far-se-á na língua do grupo a que pertençam, e em português, salvaguardado o uso da primeira.

Art. 50. A educação do índio será orientada para a integração na comunhão nacional mediante processo de gradativa compreensão dos problemas gerais e valores da sociedade nacional, bem como do aproveitamento das suas aptidões individuais.

Art. 51. A assistência aos menores, para fins educacionais, será prestada, quanto possível, sem afastá-los do convívio familiar ou tribal.

Art. 52. Será proporcionada ao índio a formação profissional adequada, de acordo com o seu grau de aculturação. (BRASIL, 1973).

Para Barros (2004, p. 47), o papel da alfabetização bilíngue para a conversão religiosa, com a tradução da Bíblia "configura um padrão de evangelização próprio para comunidades rurais pequenas" [...] "essa estratégia significou iniciar a evangelização pela tradução, diferentemente de outras missões onde essa atividade só ocorria quando já houvesse na comunidade uma igreja estruturada com pastores e crentes" (BARROS, 2004, p. 47). O interesse da missão era de "direcionar a educação indígena pública para a alfabetização na língua indígena, imprescindível ao projeto de conversão pela tradução da Bíblia" (BARROS, 2004, p. 47).

Nesse sentido, o governo militar brasileiro usou a escola com a função de evangelizar, converter, disciplinar e preparar os indígenas para ingressar no mercado de trabalho e abrandar suas lutas para preservar e ou recuperar suas terras. Os missionários do SIL, recebiam treinamento em linguística, nos Estados 
Unidos, para melhor atuarem na conversão indígena. Com uma formação aligeirada em linguística, se intitulavam doutores, escamoteando a identidade missionária passando-se por pesquisadores. Muitas foram as críticas a mais esta estratégia política integracionista e ao modelo de ensino bilíngue, sendo um estudo relevante nesta área o de Yonne Freitas Leite (LEITE, 1981).

Com a entrada do sistema capitalista em uma grande crise econômica, a partir da segunda metade dos anos de 1970 (HARVEY, 2004), aumentaram os movimentos sociais de protesto, a criação de partidos operários; fortalecidos nos anos de 1980 por exemplo, com a criação do Movimento dos Trabalhadores Rurais Sem Terra (MST), o levante do Exército Zapatista de Libertação Nacional (EZLN), no México, o movimento pelas Diretas Já, no Brasil e inúmeros outros movimentos sociais e indígenas na região pleitearam o direito à educação, saúde, terra, trabalho e melhores condições de vida para todos.

As organizações internacionais focaram a educação como elemento estratégico na formulação de políticas públicas de diversidade para agenciar os movimentos. Segundo Terry Eagleton (2005, p. 41), a cultura começa a ser importante "[...] quando uma potência imperialista é forçada a chegar a um acordo com o modo de vida daqueles que subjuga". Assim,

No decorrer dos anos oitenta acompanhando aos processos de pacificação e democratização dos países da região, se inicia a promulgação de leis de proteção e fomento das culturas originais de cada país. Materializam-se políticas educativas e de desenvolvimento e projetos nacionais que planejam uma atenção especial à educação dos povos originários. (UNESCO, 2001, p. 81).

O estado de exclusão em que as populações minoritárias se encontram devido à expropriação das terras e à exploração da força de trabalho na sociedade capitalista foi revelada em inúmeras pesquisas patrocinadas pelos organismos internacionais. Segundo estudos do Banco Mundial, (2002, p. 24) "la educación no está aprovechando su potencial para mejorar la movilidad social. Los pobres de las zonas rurales y los pueblos indígenas se encuentran en franca desventaja en comparación con otros grupos".

Em um contexto de crise e desemprego, a Educação e a alfabetização, em específico, são eleitas como prioridades para o aliviamento da pobreza. 
En la región, medio millón de niños indígenas, equivalente a un 6,3\% de los niños de entre 7 y 18 años de edad, ve vulnerado gravemente su derecho a la educación, pues no han accedido nunca a la educación formal o la han abandonado sin haber aprobado ningún año de estudio. En contraste, solo estaría en esta situación un 0,6\% de la infancia afrodescendientes y un 1,9\% del resto. (COMISSÃO ECONÔMICA PARA A AMÉRICA LATINA [CEPAL], 2012, p. 33).

A situação precária a que está submetida grande parte das sociedades indígenas após a ocupação de seus territórios, desmatamento, enfraquecimento do solo pela monocultura, poluição advinda do uso de agrotóxicos no agronegócio, e a vida de muitos, restrita a pequenas parcelas de terras em áreas rurais ou nas periferias urbanas; atinge radicalmente o futuro de crianças e jovens indígenas. Segundo estudo da OIT (2007, p. 45) "Os jovens indígenas estão entre os grupos mais vulneráveis e desprotegidos". Segundo Apple (2001, p. 122), jovens que experienciam a pobreza durante a infância tem uma probabilidade $300 \%$ maior de não concluir a escola secundária do que crianças que nunca foram pobres.

Diante desta realidade, conferências internacionais e documentos base são produzidos em parceria com as agências multilaterais que operam na região, como a Organização dos Estados Americanos (OEA), a Comissão Econômica para a América Latina (CEPAL) e outros, dando origem ao Projeto Principal de Educação (1980-2000) (PPE), comandado pela Oficina Regional de Educação para a América Latina e o Caribe (OREALC), agência da UNESCO, instalada no Chile para difundir ideais de desenvolvimento e dialogar com as demandas dos movimentos sociais.

Com a aprovação do PPE, os 30 países - Estados Membros da OEA - da região, foram convocados à adesão por meio do desenvolvimento de estratégias e ações que possibilitariam um "novo estilo" de desenvolvimento com "maior homogeneidade social." Para as agências internacionais, os grupos excluídos devem ser "[...] personas capaces de asumir su propia cultura y de incorporar a ella el progreso científico indispensable para crear, desarrollar y adaptar tecnologías apropiadas requeridas por los diversos contextos de la región" (UNESCO, 1979, p. 3).

Respaldados por enquetes e estudos realizados na América Latina, uma rede de projetos educacionais (PPE, PROMEDLAC, PRELAC) foi estabelecida no período, com reuniões regionais periódicas que garantiriam, não apenas o alcance, 
mas, principalmente, a adesão e comprometimento dos países-membros com os princípios básicos da nova política educacional envolvendo, também, mudanças na educação destinadas aos povos indígenas.

Para os organismos e organizações multilaterais, o problema da pobreza, discriminação e exclusão está na falta de conhecimentos escolares que ampliaria a todos as possibilidades de conseguir emprego ou renda, sendo a alfabetização um artefato eficaz. Preconiza-se que: "Por meio da alfabetização, os menos favorecidos podem encontrar sua voz. Por meio da alfabetização, os pobres podem aprender a aprender. Por meio da alfabetização, os sem-poder podem se empoderar" (BRASIL, 2003, p. 13).

Assim, a partir do final dos anos de 1980 e decorrer da década de 1990, a política de alfabetização bilíngue é reformulada, seu fundamento é a alfabetização bilíngue e a interculturalidade, onde os povos indígenas passam a ser considerados protagonistas e devem ser estimulados, pelas políticas públicas, a se empoderar e adquirir os direitos de cidadania participativa. As antigas concepções integracionistas são abandonadas adotando-se concepções de inclusão e autonomia. A tutela cedeu lugar à autodeterminação e auto-gestão indígena, agenciadas pelos estados plurais.

\section{A ATUAL POLÍTICA EDUCACIONAL BRASILEIRA E A EDUCAÇÃO ESCOLAR INDÍGENA}

Em meio aos movimentos sociais e às reformas neoliberais na região, as constituições foram alteradas em série (RAMOS, 2012). No Brasil os povos indígenas, antes tutelados, adquiriram o direito de cidadania e à diferença, tendo assegurado, também, o direito à utilização de suas línguas e os processos próprios de aprendizagem na educação básica. Conforme o artigo 231 da Constituição federal de 1988, "São reconhecidos aos índios sua organização social, costumes, línguas, crenças e tradições, e os direitos originários sobre as terras que tradicionalmente ocupam".

Com o Decreto Presidencial n. 26 de 1991, o Ministério da Educação assumiu a responsabilidade sobre a Educação Escolar Indígena passando a formular Diretrizes e Referenciais específicos para esta modalidade de Educação. A Lei de Diretrizes e Bases da Educação Nacional (LDBEN) n. 9394/96, em seu Artigo 78, 
A política de alfabetização bilíngue: histórico, ações para a formação de professores indígenas e a produção didática

estabeleceu a necessidade de "[...] desenvolvimento de programas integrados de ensino e pesquisa, para oferta de educação escolar bilíngue e intercultural aos povos indígenas, com os objetivos de proporcionar aos índios, suas comunidades e povos, a recuperação de suas memórias históricas". As diferentes identidades foram estimuladas e buscou-se a valorização das línguas e ciências indígenas visando garantir às comunidades, também, o acesso às informações, conhecimentos técnicos e científicos da sociedade nacional.

Um conjunto de resoluções, pareceres, portarias e referenciais somaram-se a outras tantas legislações estaduais e municipais, possibilitando a ampliação das escolas e das matrículas de crianças e jovens indígenas, maior contratação de professores indígenas, com a proposta de formações em serviço e elaboração de materiais didáticos bilíngues diferenciados com a rediscussão dos Projetos Políticos Pedagógicos, currículos e calendários escolares.

Conforme recomendação internacional destacaram-se na legislação os parâmetros da interculturalidade e do bilinguismo. Na América Latina, o termo, interculturalidade havia sido empregado nas ações do padre austríaco, Ivan Illich, na Costa Rica, México e Brasil nos anos de 1960, por ocasião da criação dos Centros de Formação Intercultural (CENFI), encarregados de promover cursos para missionários estrangeiros que atuavam com populações bilíngues.

A Conferência Mundial do México sobre Cultura e Desenvolvimento, realizada pela UNESCO em 1982, contou com a presença de renomados acadêmicos provenientes de diferentes áreas do conhecimento, instituições e países da região sendo que os resultados do debate sobre o tema, veiculados pela Revista América Indigenista (do Instituto Indigenista Interamericano - afiliado à OEA), impactou maiores segmentos sociais em torno do conceito, já difundido na Europa ocidental (FAUSTINO, 2006), adotado pela UNESCO, a interculturalidade, que vai assim, sendo absorvida, em diferentes esferas.

No âmbito das novas propostas dos organismos internacionais o conceito é usado para incorporar aos empreendimentos atuais a ideia de desenvolvimento com identidade (BENGOA, 1993). Passa então, a ser divulgada nos eventos e documentos, compondo as reformas educacionais realizadas na América Latina no período. Conforme afirmação de uma funcionária das Nações Unidas "No final dos anos de 1980, os organismos das Nações Unidas haviam criado todo um 
repertório de palavras e frases para expressar a nova conscientização sobre o meio ambiente da selva tropical e suas populações indígenas" (ZINSSER 2004, p. 74).

Como nos demais países-membros da OEA, no Brasil, desde a publicação da Convenção 169 pela OIT, em 1989, até a I Conferência Nacional da Educação Escolar Indígena (CONEEI), em 2009, decorreu-se um longo período de reformulação da legislação para a constituição de uma política de educação escolar indígena baseada nos preceitos da interculturalidade.

Em cumprimento às determinações legais como o Parecer n. 14 (BRASIL, 1999), foram sendo estadualizadas e consolidadas as instituições educativas nas Terras Indígenas, como escolas indígenas.

Embora a política tenha promovido certo investimento do país na formação de professores indígenas - por meio de cursos de Magistérios, Licenciaturas Específicas e ações afirmativas (NOVAK, 2014) flexibilizando o ingresso de indígenas em instituições de ensino superior - em decorrência dos índices históricos de escolaridade dos povos indígenas no continente, grande parte dos professores não tem formação superior (FAUSTINO; NOVAK; RODRIGUES, 2020), e atua nas escolas de forma temporária, sem concurso público e sem carreira especifica do Magistério Indígena, o que acarreta em frequente rotatividade pondo em risco os projetos interculturais conduzidos pelos professores e gestores indignas.

Em relação ao entendimento e direito à alfabetização de indígenas, o Brasil, segundo Cavalcanti (1999, p. 395), "não reconhece e não encoraja o ensino bilíngue no contexto de minorias linguísticas". Os povos, devido à garantia constitucional, possuem o direito de uma educação bilíngue, entretanto, há carência de currículos e práticas pedagógicas que priorizem o bilinguismo. Decorridos mais de 30 anos da aprovação da Constituição, e décadas após o Ministério da Educação (MEC) assumir a educação escolar indígena, predomina nas escolas o ensino de língua portuguesa e a ausência de programas e materiais de alfabetização bilíngue.

Há uma grande diversidade dos contextos bilíngues indígenas. Em algumas comunidades houve o desuso da língua indígena, sendo a língua portuguesa a L1; em outras as crianças só entram em contato, mais efetivo, com o português quando ingressam na escola. Só quando as crianças indígenas vão à escola é que "se deparam com uma língua(gem) totalmente desconhecida: o português escrito" (CAVALCANTI, 1999, p. 398). 
A política de alfabetização bilíngue: histórico, ações para a formação de professores indígenas e a produção didática

Segundo dados do IBGE, entre 2000 e 2010, o analfabetismo chegou a $33,4 \%$ para os indígenas de 15 anos ou mais, residentes em zonas rurais. A taxa de alfabetização dos indígenas com 15 anos ou mais de idade (em português e/ou no idioma indígena) passou de $73,9 \%$ para $76,7 \%$. Na questão de gênero, os dados mostram que, em 2010, a taxa de alfabetização masculina $(78,4 \%)$ era superior à feminina (75,0\%). Na área rural, a taxa de analfabetismo chegou a $33,4 \%$, sendo $30,4 \%$ para os homens e $36,5 \%$ para as mulheres. Já nas terras indígenas, $67,7 \%$ dos indígenas de 15 anos ou mais de idade eram alfabetizados. Para os indígenas autodeclarados, residentes fora das terras, a taxa de alfabetização foi 85,5\%. Tanto nas terras demarcadas quanto fora delas os homens apresentam taxas de alfabetização superiores às das mulheres. Nas áreas demarcadas, as gerações mais jovens eram mais alfabetizadas que a população acima dos 50 anos, cujas taxas de analfabetismo (52,3\% para o grupo entre 50 e 59 anos e $72,2 \%$ para 60 ou mais anos) eram maiores que as de alfabetização (47,7\% e 27,8\%, respectivamente).

As discussões provenientes da I CONEEI, aprovadas pela Resolução FNDE n. 9 (implementação dos Territórios Etnoeducacionais) Decreto n. 6.861, de 27 de maio de 2009, propôs a revisão da Lei de Diretrizes e Bases da Educação (LDBEN), Lei 9394/96 sugerindo que o poder público melhor reconheça as leis que regem esta modalidade de ensino, conforme a Constituição Federal de 1988, e garanta a oficialização das línguas indígenas nos currículos das escolas em todos os níveis, etapas e modalidade de ensino conforme a realidade linguística de cada povo.

Professores e lideranças indígenas salientaram, na CONEEI, ser imprescindível a criação de políticas educacionais voltadas para a valorização e preservação do patrimônio linguístico dos povos indígenas, apontando a necessidade de "[...] valorização, fortalecimento, revitalização das línguas indígenas nas práticas pedagógicas e para que a comunidade possa reconhecer a importância de se trabalhar a língua materna nas escolas, principalmente entre os grupos onde as línguas estão ameaçadas [...]" (BRASIL, 2009, p.31). Deve-se assegurar "[...] o ensino e a valorização das culturas e línguas indígenas, desde as séries iniciais até o ensino superior." (BRASIL, 2009, p. 31). A Conferência defendeu, ainda, em caráter de urgência a revisão do RCNEI "[...] abrindo maiores espaços de discussão e participação direta de lideranças, professores e professoras indígenas, gestores indígenas e contemplando todas as etnias e regiões brasileiras. (BRASIL, 2009, p. 26). 
No período seguinte, até 2014, com os dados do Programme for International Student Assessment (PISA) divulgados pela UNESCO, e outros indicadores estatísticos nacionais como a publicação das Estatísticas sobre Educação Escolar Indígena no Brasil (BRASIL, 2007) o governo brasileiro iniciou o desenho de programas que possibilitariam maior diversidade de abordagens e métodos pedagógicos, maior conhecimento da realidade sociolinguística e educacional dos povos indígenas no Brasil e maior formação de pesquisadores e professores indígenas.

Com uma legislação específica, diferenciada e focalizada já fortalecida no país (FAUSTINO, 2006), órgãos de fomento iniciaram a abertura de linhas de financiamento a projetos de pesquisa e extensão dando origem a trabalhos de campo com equipes de pesquisa interdisciplinares que resultaria em um melhor conhecimento das realidades, culturais, linguísticas e educacionais e experiências de alfabetização indígena, em curso no país.

Segundo a UNESCO (1997), mesmo parecendo haver o consenso geral de que a criança aprende a ler e escrever de maneira mais efetiva na língua materna, muitos povos indígenas latino-americanos são ambivalentes a respeito e consideram que não lhes deve ser negada a oportunidade de aprender bem a língua da sociedade dominante.

Em relação ao bilinguismo nas escolas indígenas, embora existam vários trabalhos acadêmicos já publicados e algumas experiências divulgadas, as pesquisas não trazem à tona o estado da arte da alfabetização bilíngue no Brasil, sendo difícil o reconhecimento de um panorama mais geral, dos programas e métodos bilíngues desenvolvidos após o MEC ter assumido o controle da Educação Escolar Indígena e os programas implementados a partir de 2004.

Levantamento (BERNARDINO, 2015) realizado no Bando de dados da Coordenação de aperfeiçoamento de Pessoal de Nível Superior (CAPES), evidenciou que a produção na área abrange temas como a oralidade e da escrita na EEI; os currículos, a autonomia indígena, o ensino de variadas matérias, a formação dos professores, as diferentes formas de aprendizagem e outros temas afetos às populações indígenas. Dentre estes temas, recorrentes nas produções da área, não foram encontrados estudos que tematizem, especificamente, teorias e métodos de alfabetização bilíngue. 


\section{A ALFABETIZAÇÃO BILÍNGUE EM LÍNGUAS INDÍGENAS}

Com a construção de uma política de alfabetização bilíngue que data da segunda metade do século XX, estudos (UNESCO, 1954) passam a defender que os indígenas aprendem a escrever melhor se a alfabetização for em suas próprias línguas. O trabalho do SIL, nos anos de 1960 a 1980, produziu alguns materiais escritos em formatos de cartilhas e estas iniciaram o ensino da língua indígena escrita entre alguns povos como os Guarani e Kaingang que habitam a região sul do pais.

O método usado pelo modelo de educação do SIL pauta-se em um tipo de bilinguismo técnico/religioso, cujo objetivo foi "aprender e decodificar as línguas indígenas para realizar a tradução de textos bíblicos e abrir caminho à conversão indígena ao protestantismo via a escola" (FAUSTINO, 2006, p. 233).

Estando presente nos anos iniciais da escolarização, o modelo de bilinguismo implantado pelo SIL/FUNAI, é chamado de bilinguismo de transição, ou bilinguismo de ponte (CAVALCANTI, 1999). Neste, a língua materna é usada como caminho para ensinar a língua nacional. Parte-se da língua materna indígena, conhecida pela criança na oralidade, ficando facilitada a relação fonema/grafema, podendo-se perceber que com a escrita é possível representar a fala. Compreendida a função da escrita, com a apropriação do alfabeto e dos conjuntos silábicos, torna-se possível a leitura e escrita de pequenos textos escolares.

A Unesco, por meio da Oficina Regional de Educación para América Latina y el Caribe (OREALC/UNESCO), criada em 1963, publicou a Recopilación de materiales didácticos en educación indígena (AMADIO; D'EMILIO, 1990) no qual se pode perceber as estratégias pedagógicas utilizadas na produção didática para a alfabetização bilíngue em contextos indígenas e a renovação das recomendações para a formação de professores e a produção didática.

Segundo este estudo, por ensino da língua materna entende-se "[...] sua utilização instrumental para o tratamento dos conteúdos educacionais contemplados nos programas escolares inseridos na disciplina específica de línguas" (AMADIO; D'EMILIO, 1990, p. 67). Salientou-se que, muitas vezes, nas disciplinas de matemática, história e outras, o ensino em língua indígena se limita a tradução de conceitos e conhecimentos próprios da cultura hegemônica e a apresentação de alguns elementos isolados da cultura indígena, sem nenhum tratamento 
sistemático do saber próprio desta última nem a intenção de estabelecer relações contrastivas entre ambas. Segundo o estudo, pode ocorrer, também, no desenvolvimento da educação bilíngue intercultural, de se assumir, implicitamente, que a língua e a cultura indígena já são conhecimentos dominados pelos indígenas ou que o adquirirão em outros âmbitos, não sendo necessário à escola, o tratamento sistemático de todos seus aspectos.

A análise das estratégias pedagógicas e materiais didáticos para alfabetização em línguas indígenas, de diferentes países da América Latina (AMADIO; D'EMILIO, 1990, p. 68), demostrou que alguns projetos definem as disciplinas que serão ministradas em línguas indígenas e as que serão ministradas na língua majoritária. Outros utilizam, alternadamente as duas línguas em todas as disciplinas, de acordo com o conteúdo a ser tratado. Há, ainda, projetos que consideram necessário desenvolver todos os conteúdos nas duas línguas com o objetivo de garantir a ampliação dos códigos, registros e léxicos das línguas indígenas que, devido à progressiva restrição de seu uso nas esferas sociais globais, não tem tido a possibilidade de adequar-se aos avanços do mundo moderno em termos de significar novos elementos e acontecimentos, sendo mais frequente, recorrer a empréstimos da língua dominante.

Segundo o estudo, a padronização, normatização e desenvolvimento linguístico das línguas indígenas se configura como as áreas de maior importância para a devida implementação de uma educação bilíngue, sobretudo considerando que as experiências neste caminho, ainda são incipientes (AMADIO; D'EMILIO, 1990, p. 68). Afirma-se que um projeto de educação bilíngue intercultural deve oportunizar "o desenvolvimento intelectual e expressivo da língua materna do estudante indígena permitindo que este se torne um agente produtor de conhecimento e, portanto, de cultura" (AMADIO; D’EMILIO, 1990, p. 70).

Destaca-se a necessidade de desenvolvimento de políticas linguísticas referentes aos grupos indígenas, projetos e programas de formação de professores associados à implementação de estratégias para a promoção de mudanças de atitudes com a valorização das línguas indígenas nos meios de comunicação de massa (revistas, jornais, rádio, televisão), criação de disciplina de línguas indígenas nos cursos universitários, com o objetivo de informar, sensibilizar e conscientizar as sociedades sobre as línguas e problemáticas indígenas. A criação de disciplinas 
A política de alfabetização bilíngue: histórico, ações para a formação de professores indígenas e a produção didática

obrigatórias relacionadas às línguas, história, sociedade e culturas indígenas, em cursos superiores destinados à formação de professores, principalmente em regiões com a presença significativa de populações indígenas, segundo o estudo (AMADIO; D'EMILIO, 1990), estimularia a produção e divulgação de materiais educativos e o desenho de metodologias de trabalho apropriadas.

Em relação aos fundamentos da educação bilíngue, um estudo publicado pela UNESCO/OREALC (1989, p. 118), afirma que, entre os princípios que regem a atividade educativa, existe um que é de suma relevância: "a educação deve adequar-se às características dos educandos e de sua realidade", tanto nas metas como nos objetivos, metodologias e conteúdos sendo este o encaminhamento que assegura uma adequada consonância entre as necessidades educativas do indivíduo em formação e as exigências do meio social e natural do qual faz parte.

[...] o êxito ou fracasso escolar de qualquer criança na escola está intimamente relacionado com seu êxito ou fracasso na aquisição e desenvolvimento de determinadas habilidades linguísticas. Sua habilidade para escutar e para falar e a forma pela qual a escola o ajuda a desenvolver essas capacidades determinarão seu progresso na leitura e o avanço da escolaridade, inclusive em nível secundário e universitário. A língua constitui um valioso instrumento que ajuda a criança a desenvolver-se psicológica, social e intelectualmente. (UNESCO; OREALC, 1989, p. 119).

A pesquisa evidencia que é comum lideranças indígenas afirmarem não ser necessário o ensino da língua indígena na escola uma vez que a comunidade e as crianças já a conhecem, e que a escola deve ensinar o que as crianças não sabem, ou seja, a língua da sociedade majoritária para que tenham melhores oportunidades no futuro e não sofram preconceitos como as gerações passadas sofreram.

Esta crença só poderá ser alterada a partir de ações de formação de professores onde se desenvolvam as ideias de que a escola tem como uma de suas funções centrais promover o aprofundamento e a complexificação dos conhecimentos prévios que as crianças já tem visando seu maior desenvolvimento intelectual. Em se tratando de uma escola indígena, situada em diferentes contextos culturais e linguísticos, a escola necessita, também, sistematizar conhecimentos e compreender os aspectos dos processos próprios de aprendizagem comunitárias.

Atualmente, por meio das legislações vigentes, a partir dos anos de 1980, a alfabetização da criança indígena deve pautar-se em uma educação bilíngue 
e intercultural, isto é, o ensino e aprendizagem da língua indígena e da língua portuguesa, com conteúdos relevantes às culturas indígenas e conduzidas pelos próprios índios. Uma educação bilíngue com este encaminhamento, afirma Amaral (2011, p. 4), "[...] pode contribuir de forma decisiva para a manutenção de línguas minoritárias que sofrem forte pressão das línguas nacionais".

\section{A FORMAÇÃO DE PROFESSORES E A PRODUÇÃO DE MATERIAIS DIDÁTICOS NO CONTEXTO DA AÇÃO SABERES INDÍGENAS NA ESCOLA, NO BRASIL}

O Censo do IBGE de 2010 (IBGE, 2010) informou que existem 274 línguas indígenas faladas no Brasil por pessoas pertencentes a 305 etnias indígenas diferenciadas. Informou, ainda, que 37\% dos indígenas, com mais de 5 anos, falam as línguas e suas variações dialetais, sendo que milhares de indígenas, falam mais de duas línguas.

Mesmo diante desta rica realidade sociolinguística, raros são os livros, jornais, revistas e outros meios escritos em línguas indígenas. Pesquisa realizada pelo Instituto Nacional de Estudos e Pesquisas em Educação (INEP), no início do século XXI (BRASIL, 2007), demonstrou que ainda são raríssimas as produções em línguas indígenas existentes nas escolas indígenas.

Os professores indígenas enfrentam muitas dificuldades ao preparar suas aulas interculturais bilíngues, devido, principalmente, à ausência de materiais didáticos apropriados e de espaços para estudos sobre o bilinguismo.

Conforme o Referencial Curricular Nacional para as Escolas Indígenas (BRASIL, 1998), p. 152), "[...] os cursos de formação de professores indígenas devem ter como objetivo criar condições para que eles se tornem capazes de fazer pesquisas e realizar trabalhos de produção e materiais didáticos específicos e bilíngues.

No Artigo 7 das Diretrizes Curriculares Nacionais para a Educação Escolar Indígena, § 4으, afirma-se que "A Educação Escolar Indígena será acompanhada pelos sistemas de ensino, por meio da prática constante de produção e publicação de materiais didáticos diferenciados, na língua indígena, em português e bilíngues, elaborados pelos professores indígenas [...], para todas as áreas de conhecimento" (BRASIL, 2012, p. 4). 
A política de alfabetização bilíngue: histórico, ações para a formação de professores indígenas e a produção didática

No Artigo 20, § 4으, orienta-se que "A formação de professores indígenas deve estar voltada para a elaboração, o desenvolvimento e a avaliação de currículos e programas próprios, bem como a produção de materiais didáticos específicos e a utilização de metodologias adequadas de ensino e pesquisa" (BRASIL, 2012, p. 10).

A partir de dados da realidade, dos referenciais e diretrizes, o governo brasileiro, no período, iniciou programas de formação continuada, que possibilitassem a pesquisa em equipes com a presença de professores indígenas criando condições de estudos, encontros, discussões e produção de recursos didáticos bilíngues, em diferentes linguagens e portadores de textos.

Desenvolveu-se, assim, a Ação Saberes Indígenas na Escola (SIE), um Programa de formação continuada com professores indígenas, desenvolvido pelas instituições de ensino superior (IES), em regime de colaboração com os estados e municípios, baseada nos princípios da especificidade, da organização comunitária, do multilinguismo e da interculturalidade integrando o eixo Pedagogias Diferenciadas e Uso das Línguas Indígenas do Programa Nacional dos Territórios Etnoeducacionais Indígenas, instituído pela Portaria MEC n. 1.062, de 30 de outubro de 2013.

Tem como objetivos promover a formação continuada de professores indígenas da educação básica, especialmente daqueles que atuam nos anos iniciais do ensino fundamental nas escolas indígenas; desenvolver recursos didáticos e pedagógicos que atendam às especificidades da organização comunitária e do multilinguismo; oferecer subsídios à elaboração de currículos, definição de metodologias e processos de avaliação que atendam às especificidades dos processos de letramento, numeramento e conhecimentos dos povos indígenas; fomentar pesquisas que resultem na elaboração de materiais didáticos e paradidáticos em diversas linguagens, bilíngues e monolíngues, conforme a situação sociolinguística de cada povo e de acordo com as especificidades da educação escolar indígena.

A formação busca contemplar a complexidade etno-sociolinguística dos povos indígenas atendidos, e realiza-se com base nos seguintes eixos: letramento e numeramento em línguas indígenas como primeira língua; letramento e numeramento em língua portuguesa como primeira língua; letramento e numeramento em línguas indígenas ou língua portuguesa como segunda língua ou língua adicional; e, conhecimentos e artes verbais indígenas. 
Esta ação conta com a adesão de 23 instituições de ensino superior organizadas em seis redes, intituladas RIES. Cada Rede é constituída pela instituição sede, com uma coordenação geral e pelas instituições núcleos, atuando em estados e municípios que possuem escolas indígenas em suas redes de ensino. Na etapa inicial, o SIE abrangeu treze Territórios Etnoeducacionais, com mais de duzentas escolas indígenas, atendendo cerca de noventa povos territorializados em mais de duzentas e cinquenta aldeias onde são faladas mais de sessenta línguas indígenas.

As IES envolvidas possuem reconhecida experiência na área de pesquisa, formação de professores, pesquisadores e pós-graduandos indígenas, bem como na produção e materiais didáticos para os anos iniciais da educação básica.

Cada Núcleo, em consonância com sua Rede e em amplo debate com os povos envolvidos, estabeleceu procedimentos formativos próprios de acordo com as diferentes realidades sociolinguísticas de cada região. Os eventos de formação possibilitaram a realização de encontros e rituais com a participação de sábios e rezadores e riquíssimas trocas de experiências entre professores alfabetizadores indígenas promovendo a produção de variados materiais, como Cartilhas e Coletâneas de Alfabetização e livros de memórias e saberes, livros paradidáticos com conteúdos de narrativas dos sábios mais velhos, professores e estudantes indígenas (SOUSA; SOUZA, 2017; WAHUKA, 2016); Os materiais, produzidos em diferentes linguagens, no âmbito da formação da ação Saberes Indígenas na Escola disponibilizados em diversos formatos, pelas IES que compõem as redes ação.

Inaugurou-se assim, no Brasil, um programa abrangente, que conta com participação indígena em seus locais e possibilita uma efetiva formação continuada de professores em serviço, com planejamentos pedagógicos, organização para pesquisas de campo junto às suas comunidades, estudos e sistematizações de saberes ancestrais e conteúdos escolares que fortalecem as línguas e culturas indígenas dando suporte à uma produção didática própria e especifica para alfabetização e desenvolvimento do ensino aprendizagem nas diferentes etapas da escolarização.

Alfabetização e escolarização, em todos os seus níveis, tem sido uma reivindicação dos povos indígenas no Brasil. Conforme a I Conferência Nacional de Educação Escolar Indígena (BRASIL, 2009), indígenas de todas as regiões apresentaram as demandas de suas comunidades, especificando-as e a luta por materiais didáticos bilíngues, feitos pelos próprios indígenas, é central. 
A política de alfabetização bilíngue: histórico, ações para a formação de professores indígenas e a produção didática

Partimos do entendimento de que alfabetizar envolve habilidades básicas de decodificação e codificação, ou seja, ensinar uma criança a ler e escrever é um processo que deve ser acompanhado de uma profunda reflexão entre a equipe de professores e gestores de uma escola. Para tanto, exige-se do/a professor/a alfabetizador/a o conhecimento e a adoção de uma concepção de ensino e aprendizagem que oriente suas práticas e lhe possibilite compreender que as crianças, ao ingressarem na escola, passam a se envolver em situações de transmissão de conhecimentos que podem reconhecer, valorizar e potencializar os conhecimentos próprios, ou negá-los e subalternizá-los, impondo o modelo ocidental predominante.

\section{CONSIDERAÇÕES FINAIS}

Após vertiginosos movimentos sociais ocorridos no século $X X$, como a Revolução Russa, que consolidou direitos sociais e linguísticos às minorias, organizações internacionais em países ocidentais foram criadas, no pós-guerra, para viabilizar direitos humanos e a educação para todos.

Embora a educação escolar para povos indígenas tenha um histórico de imposição, disciplinarização e conversão, desde as últimas décadas do século XX, os movimentos indígenas situam a escola ressignificada, como um local de apoio às práticas de revitalização cultural, fortalecimento identitário e lugar onde se aprendem conteúdos universais que devem ser intercambiados com os conhecimentos tradicionais, as lutas e resistências indígenas e assim se construir uma educação intercultural e bilíngue.

Respeitando-se as pautas dos povos, a alfabetização e a produção didática para todos as etapas e níveis da educação devem ter essa educação diferenciada e especifica (bilíngue e intercultural) como princípio central

As inúmeras convenções, documentos e tratados sobre o tema, evidenciam um contínuo avanço do direito internacional no reconhecimento da diversidade sociocultural e linguística nas diferentes regiões do mundo. Tem havido um crescimento na alfabetização dos povos indígenas, porém, faltam dados governamentais consistentes sobre a aprendizagem bilíngue. Os dados sobre a presença da língua na alfabetização e as metodologias utilizadas nas escolas indígenas ainda carecem de melhor investigação por parte do Estado brasileiro e estas devem ser realizadas com a presença de pesquisadoras/es indígenas. 
Os professores indígenas, em práticas escolares, atuam na busca da revitalização da cultura e da língua, no fortalecimento das identidades étnicas e na elaboração de currículos interculturais articulados aos demais conhecimentos científicos universais, por meio da escola. Registra-se a necessidade de ampliar as práticas pedagógicas e melhorar as estratégias para o ensino e a aprendizagem da língua indígena oral e escrita, visando à maior valorização e presença delas em todas as etapas nas escolas indígenas e pela sociedade envolvente em geral.

Há Terras em que predomina o uso da língua indígena em todas as situações cotidianas. Há Terras em que o bilinguismo é acentuado havendo grupos familiares com distintas formas de uso das línguas indígena e portuguesa. Há Terras em que a língua portuguesa impôs-se como primeira língua e a língua indígena é usada em manifestações religiosas, sendo reaprendida por meio da escola. Nas Terras em que a língua indígena é a segunda língua, sempre há falantes da língua indígena, principalmente alguns velhos, e é a partir daí, buscando diferentes matrizes epistemológicas, que se pode fazer um trabalho aprofundado na escola com as línguas e os saberes indígenas.

Jovens e crianças, assim como as comunidades, necessitam ser envolvidos nos projetos interculturais e na produção didática para as escolas, trazendo novas palavras, expressões, cantos e rezas, histórias e narrativas de seus povos. Conforme as políticas públicas atuais e uma extensa legislação, elaborada a partir Constituição brasileira de 1988, tem-se priorizado a formação continuada nas próprias comunidades, a exemplo dos Saberes Indígenas na Escola, o que oportuniza este trabalho de produção coletiva situada.

Dessa forma, entendemos que pesquisas de campo sobre a temática e a publicação de seus resultados são fundamentais para o avanço das discussões sobre alfabetização e o bilinguismo em escolas indígenas, uma vez que são grandes os desafios dos professores indígenas que visam atender aos anseios de suas comunidades, ou seja, preparar os alunos para enfrentar os desafios de sobreviver na sociedade atual e, por outro lado, lutar pela manutenção da língua indígena, de forma que esta esteja bem posicionada e avance, também, via escolas indígenas. 
A política de alfabetização bilíngue: histórico, ações para a formação de professores indígenas e a produção didática

\section{REFERÊNCIAS}

AMADIO, Massimo; D’EMILIO, Anna Lucía (Comp.) Recopilación de materiales didácticos en educación indígena. Santiago-Chile: UNESCO/OREALC, 1990.

AMARAL, Luiz. Bilinguismo, aquisição, letramento e o ensino de múltiplas línguas em escolas indígenas no Brasil. Cadernos de Educação Escolar Indígena, Cáceres, v. 9, n. 1, p. 13-32, 2011.

APPLE, Michael W. Política cultural e educação. São Paulo: Cortez, 2001.

BANCO MUNDIAL. Llegando a los pobres de las zonas rurales: estrategia de desarrollo rural para América Latina y el Caribe. Washington: Banco Mundial, 2002.

BARROS, Maria Cândida D. M. Linguística missionária: Summer Institute of Linguistics. 1993. Tese (Doutorado em Filosofia e Ciências Sociais) - Universidade Estadual de Campinas, Campinas, SP,1993.

BARROS, Maria Cândida Drumond Mendes. A missão Summer Institute of Linguistics e o indigenismo latino-americano: história de uma aliança (décadas de 1930 a 1970). Revista de Antropologia, São Paulo, v. 47, n. 1, p. 45-85, 2004.

BENGOA, José. Desarrollo con identidad: la cuestión del desarrollo indígena en America Latina. In: UQUILLAS, Jorge E.; RIVERA, Jean-Carlo. Pueblos indígenas y desarrollo en America Latina. Washington: Banco Mundial, 1993. p.73-82.

BERNARDINO, Mariana Mendonça. Educação Escolar Indígena: política, debates e ações para a alfabetização na Perspectiva da Teoria Histórico-Cultural. Dissertação (Mestrado em Educação) - Universidade Estadual de Maringá, Maringá, PR, 2015.

BITTAR, Marisa; FERREIRA JR., Amarilio. Ativismo pedagógico e princípios da escola do trabalho nos primeiros tempos da educação soviética. Revista Brasileira de Educação, v. 20, n. 61, abr./jun. 2015.

BRASIL. Ministério da Educação. Diretrizes Curriculares Nacionais para a Educação Escolar Indígena na Educação Básica. Brasília-DF: Ministério da Educação; Conselho Nacional de Educação; Câmara de Educação Básica, 2012. Disponível em: http://mobile.cnte.org. br:8080/legislacao-externo/rest/lei/86/pdf. Acesso em: 23 jul. 2020.

BRASIL. Ministério da Educação. Parecer 14/1999. Diretrizes Curriculares Nacionais da Educação Escolar Indígena. Brasília-DF: Ministério da Educação, 1999. 
BRASIL. Lei n. 6.001. Estatuto do Índio. Diário Oficial da União, Brasília, p. 13.177, seção I, 21 de dezembro de 1973.

BRASIL. Ministério da Educação. Referencial Curricular Nacional para as Escolas indígenas. Brasília-DF: MEC/SECADI, 1998.

BRASIL. Alfabetização como liberdade. Brasília-DF: UNESCO/MEC, 2003. Disponível em: http://www.dominiopublico.gov.br/download/texto/ue000001.pdf. Acesso em: 13 jul. 2020.

BRASIL. Ministério da Educação. In: CONFERÊNCIA NACIONAL DE EDUCAÇÃO ESCOLAR INDÍGENA,1., Brasília, Secretaria de Educação Continuada, Alfabetização, Diversidade e Inclusão. Anais [...]. Brasília-DF: SECADI, 2009.

BRASIL. Instituto Nacional de Estudos e Pesquisas Educacionais Anísio Teixeira. Estatísticas sobre educação escolar indígena no Brasil. Brasília-DF: INEP, 2007. Disponível em: http:// www.publicacoes.inep.gov.br/arquivos/\%7B7BF2B332-7B8F-44A5-9F2A-282D5E57FB24 \%7D_2educacaoindigenabrasil.pdf. Acesso em: 14 set. 2019.

CAVALCANTI, C. Marilda. Estudos sobre educação bilíngue e escolarização em contextos de minorias linguísticas no Brasil. D.E.L.T.A., v. 15, n. especial, p. 385-417, 1999. Disponível em: https://www.scielo.br/pdf/delta/v15nspe/4023.pdf. Acesso em: 19 jun. 2020.

COLLET, Celia Letícia Gouvêa. Interculturalidade e educação escolar indígena: um breve histórico. Formação de professores indígenas repensando trajetórias. Brasília-DF: MEC/ SECAD-UNESCO, 2006.

COMISSÃO ECONÔMICA PARA A AMÉRICA LATINA [CEPAL]; FUNDO DAS NAÇÕES UNIDAS PARA A INFÂNCIA [UNICEF]. Pobreza infantil en pueblos indígenas y afrodescendientes en America Latina. Santiago de Chile: ONU, 2012. Disponível em: https://www.cepal.org/ es/publicaciones/3981-pobreza-infantil-pueblos-indigenas-afrodescendientes-americalatina. Acesso em: 25 mar. 2015.

DESHERIEV, Yunus D. Progreso social y sociolinguística. Revista Internacional de Ciencias Sociales, v. XXXVI, n. 1, [s.p.], 1984.

EAGLETON, Terry. A ideia de Cultura. Tradução de Sandra Castello Branco. São Paulo: Editora da Unesp, 2005.

FAUSTINO, Rosângela C. Política educacional nos anos de 1990: o multiculturalismo e a interculturalidade na educação escolar indígena. 2006. 335 f.Tese (Doutorado em Educação) - Universidade Federal de Santa Catarina, Florianópolis, SC, 2006. 
A política de alfabetização bilíngue: histórico, ações para a formação de professores indígenas e a produção didática

FAUSTINO, Rosangela Celia; NOVAK, Maria Simone Jacomini; RODRIGUES, Isabel Cristina. $\mathrm{O}$ acesso de mulheres indígenas à universidade: trajetórias de lutas, estudos e conquistas. Tempo e Argumento, Florianópolis, v. 12, n. 29, [s.p.], 2020.

HARVEY, David. Condição pós-moderna. Tradução de Adail Ubirajara Sobral e Maria Stela Gonçalves. 13. ed. São Paulo: Edições Loyola, 2004.

INSTITUTO BRASILEIRO DE GEOGRAFIA E ESTATÍSTICA. Censo Demográfico 2010: características gerais dos indígenas - resultados do universo. Rio de Janeiro: IBGE, 2010. Disponível em: https://biblioteca.ibge.gov.br/visualizacao/periodicos/95/cd_2010_ indigenas_universo.pdf Acesso em: 26 mar. 2020

LEITE, Yonne. O Summer Institute of Linguistics: estratégias de ação no Brasil. Religião e Sociedade, Rio de Janeiro, n. 7, 1981.

LISBÔA, Flavia Marinho. Interculturalidade, letramento e alternância como fundamentos para a educação indígena. Trabalho em Linguística Aplicada, Campinas, v. 56, n. 2, p. 669-88, maio/ago. 2017.

MERIAM, Lewis et al. The problem of indian administration. The Institute for Government Research. Studies in Administration. U.S.A.: The Johns Hopkins Press Baltimore Maryland, 1928. Disponível em: https://files.eric.ed.gov/fulltext/ED087573. pdf. Acesso em: 12 mar. 2020

NOVAK, Maria Simone Jacomini. Os organismos internacionais, a educação superior para indígenas nos anos de 1990 e a experiência do Paraná: estudo das ações da Universidade Estadual de Maringá. 2014. 342f. Tese (Doutorado em Educação) - Universidade Estadual de Maringá, Maringá, PR, 2014.

ONU. Pacto Internacional dos Direitos Civis e Políticos. Adotado pela Resolução n. 2.200 A (XXI) da Assembleia Geral da Organização das Nações Unidas, em 16 de dezembro de 1966. Disponível em: http://www.rolim.com.br/2002/_pdfs/067.pdf. Acesso em: 22 ago. 2020.

ORGANIZAÇÃO INTERNACIONAL DO TRABALHO. Convenção 107 da OIT, concernente às populações indígenas e tribais. Genebra, 26 de junho de 1957. Disponível em: https:// www.oas.org/dil/port/1957\%20Conven\%C3\%A7\%C3\%A30\%20sobre\%20Povos\%20 Ind\%C3\%ADgenas\%20e\%20Tribais.\%20(Conven\%C3\%A7\%C3\%A30\%200IT\%20n\%20 \%C2\%BA\%20107).pdf. Acesso em: fev. 2020.

RAMOS, Alcida Rita. Constituições nacionais e povos indígenas. Belo Horizonte: Editora da UFMG, 2012. 
RIES, Nicholas M; HUGUES, John.; SAER, D. J. El bilinguismo y la educación: ediciones, la lectura. Madrid: Espasa Calpe, 1932.

SOUSA, Neimar Machado; SOUZA, Teodora. Saberes indígenas: vivência e convivência. Humanidades \& Inovação, Palmas, v. 4, n. 3, 2017. Disponível em: https://revista.unitins. br/index.php/humanidadeseinovacao/article/view/388. Acesso em: 15 jun. 2020.

TOWNSEND, Guillermo C. El aspecto romántico de la investigación lingüística. Peru Indígena, Lima, v. 1, n. 2, p. 39-43, 1949.

UNESCO. Informe de la reunión de especialistas organizada por la UNESCO en 1951. Empleo de las lenguas vernáculas en la enseñanza. Santiago: UNESCO, 1954.

UNESCO. A declaração das raças da UNESCO. [S.I.]: UNESCO, 18 jul. 1950. Disponível em: http://www.achegas.net/numero/nove/decla_racas_09.htm. Acesso em: 15 jun. 2020.

UNESCO. Convenção relativa a luta contra a discriminação no campo do ensino. UNESCO, 1960. Disponível em: https://unesdoc.unesco.org/ark:/48223/pf0000132598_por. Acesso em: 12 jun. 2020.

UNESCO. Declaración de Ciudad de México. In: CONFERENCIA REGIONAL DE MINISTROS DE EDUCACIÓN Y DE MINISTROS ENCARGADOS DE LA PLANIFICACIÓN ECONÓMICA DE LOS ESTADOS MIEMBROS DE AMÉRICA LATINA Y EL CARIBE. México, 4-13 de diciembre de 1979. México: UNESCO, 1979. Disponível em: http://unesdoc.unesco.org/ images/0015/001599/159987S.pdf Acesso em: 12 mar. 2020.

UNESCO; CONFITEA. Los derechos universales, la alfabetización y la educación básica: alfabetización multilingüe e intercultural. Alemania: [s.n.], 1997. Disponível em: http:// www.unesco.org/education/uie/confintea/pdf/3e_span.pdf. Acesso em: 15 jun. 2020.

UNESCO; OREALC. Educação intercultural bilíngüe. In: UNESCO; OREALC. Balanço dos 20 anos do Projeto Principal de educação na América Latina e no Caribe In: REUNIÃO DO COMITÊ REGIONAL INTERGOVERNAMENTAL DO PROJETO PRINCIPAL DE EDUCAÇÃO, 7., Documento de trabalho, 2001. Anais [...]. UNESCO, 2001

UNESCO. OREALC. Materiales de apoyo para la formación docente en educación bilingüe intercultural: Lengua. Santiago: UNESCO, set. 1989. 139 p.

VIGOTSKI, L. S. A construção do pensamento e da linguagem. Tradução de Paulo Bezerra. São Paulo: Editora Martins Fontes, 2009. 
A política de alfabetização bilíngue: histórico, ações para a formação de professores indígenas e a produção didática

WAHUKA, Sinvaldo de Oliveira. Saberes Indígenas na Escola. Revista Articulando e Construindo Saberes, v. 1 n. 1, 2016. Disponível em: https://www.revistas.ufg.br/racs/ article/view/43004. Acesso em: 15 jun. 2020.

WIESEMANN, Ursula. Children of mixed marriage in relation to Kaingang society. Revista do Museu Paulista, São Paulo, v. XV, p. 315-7, 1964.

WIESEMANN, Ursula. Semantic categories of "good" and "bad" in relation to Kaingang personal names. Revista do Museu Paulista, São Paulo, n. 12, p. 177-84, 1960.

WIESEMANN, Ursula. Notas sobre Proto-Kaingáng: um estudo de quatro dialetos. Tradução de Miriam Lemle. Rio de Janeiro: SIL, 1959. [Comunicação apresentada à 4a Reunião da ABA, Curitiba, manuscrito].

ZINSSER, Judith P. Una nueva colaboración: la de los pueblos autóctonos y el sistema de las Naciones Unidas. Museum Internacional, Paris, UNESCO, v. 56, n. 224, p. 69-83, dez. 2004.

\section{Sobre os autores:}

Rosangela Célia Faustino: Pós-Doutora em Conhecimento e Inclusão Social em Educação pela Universidade Federal de Minas Gerais (UFMG). Doutora em Educação pela Universidade Federal de Santa Catarina (UFSC). Mestre em Fundamentos da Educação pela Universidade Estadual de Maringá (UEM). Graduada em Pedagogia pela Faculdade Instituto Superior de Educação do Paraná (FAINSEP) e em História pela UEM. Professora das licenciaturas de Pedagogia na UEM e Pedagogia Indígena na Universidade Estadual do CentroOeste (UNICENTRO). Atua no Programa de Pós-Graduação em Educação da UEM (Mestrado e Doutorado), Linha: Políticas e Gestão da Educação. E-mail: rcfaustino@uem.br, ORCID: https://orcid.org/0000-0002-0094-5528

Marcos Gehrke: Doutor e mestre em Educação pela Universidade Federal do Paraná. Graduado em Pedagogia pela Universidade Regional do Noroeste do Estado do Rio Grande do Sul. Professor adjunto da Universidade Estadual do Centro-Oeste (UNICENTRO) e do Programa de Pós-Graduação em Educação. Coordenador do Curso de Pedagogia para Indígena. E-mail: marcosgehrke@gmail.com, ORCID: http://orcid.org/0000-0002-7592-3139

Maria Simone Jacomini Novak: Doutora e mestre em Educação pela Universidade Estadual de Maringá (UEM). Graduada em História pela UEM e em Pedagogia pela Faculdade Instituto Superior de Educação do Paraná (FAINSEP). Pró-reitora de Ensino de Graduação da Universidade Estadual do Paraná (UNESPAR). Professora Adjunta C/TIDE do curso de Pedagogia na UNESPAR. Pesquisadora do 
Programa Interdisciplinar de Estudos de Populações/Laboratório de Arqueologia, Etnologia e Etno-História (CCH-UEM).E-mail: maria.novak@unespar.edu.br, Orcid: https://orcid.org/0000-0002-3820-6579

Recebido em: 26 de outubro de 2020.

Aprovado para publicação em: 3 de novembro de 2020. 